\title{
Construction of Concrete Canoe using Light Weight Aggregates
}

\author{
Sanjay Jayakumar ${ }^{1}$, Abhishek Kurian ${ }^{2}$, Febin T Zachariah ${ }^{3}$, Nivin Philip ${ }^{4}$ \\ ${ }^{1}$ UG Scholar, Department of Civil Engineering, SAINTGITS college of Engineering, Kerala, India \\ ${ }^{2}$ UG Scholar, Department of Civil Engineering, SAINTGITS college of Engineering, Kerala, India \\ ${ }^{3}$ PG Scholar, Department of Civil Engineering, SAINTGITS college of Engineering, Kerala, India \\ ${ }^{4}$ Associate Professor, Department of Civil Engineering, SAINTGITS college of Engineering, Kerala, India
}

\begin{abstract}
The history of construction of concrete boats and canoes extends as far back to World War II in 1939, however the first concrete boat was constructed in 1848 in France. Due to the shortage of timber and steel during the World Wars, concrete boats came into action. The construction of a concrete canoe requires the usage of light weight concrete where the conventional coarse aggregates are replaced by lightweight aggregates. Neglecting the hydrodynamic effects, all boats and ships float on the surface of water due to their capacity to displace the weight of water with the weight of the boat. In a Concrete canoe we are using lightweight concrete mixes to enhance the strength parameters of the canoe along with reducing its weight so that it can acquire the desired floating property. Usually concrete boats and ships were commercially constructed using Ferro cement. Since the materials of construction are readily available and cheap many of the Naval structures were earlier profoundly constructed using concrete. But as time passed by, the rising of the labour costs and operating difficulties the industry faced lack of investments which eventually brought it to an abrupt stop. The efforts to inculcate and develop innovative ideas and Engineering skills by the American Society of Civil Engineers( ASCE) brought about a turn of events in the concrete canoe construction process. Now each year students from various parts of the globe meet and compete with each other in the National Concrete Canoe Competition (NCCC). This study which was established to compete in the National Concrete Canoe Competition, deals with the construction of a concrete canoe having perfect floating property including sufficient stability and adequate compressive strength.
\end{abstract}

Key Words: Concrete, Coarse aggregate, Lightweight concrete, Concrete canoe

\section{INTRODUCTION}

Concrete is a composite material which consists of aggregates, water and cement. Various experiments have been conducted in concrete over the years to increase the strength as well as other properties by using different materials including various types of cement, aggregates and chemical admixtures. Such research works have led to the discovery of lightweight concrete having reduced density, and thus weight. After the world war II, light weight concrete was put in the market as a newly emerged building material. The density of light weight concrete falls between 1140 to $1840 \mathrm{~kg} / \mathrm{m}^{3}$ and it depends on the relative density of light weight aggregates[2]. The reduced density of light weight concrete is achieved by using aggregates such as expanded clay, perlite, vermiculite, EPS beads etc[3,4,5].

The usage of light weight aggregates has drastically reduced the overall mass of concrete when compared to nominal concrete. However, attaining the characteristic strength of nominal concrete was indeed a challenge. Numerous concrete test cubes of size $0.15 \times 0.15 \times 0.15 \mathrm{~m}^{3}$ were casted using cementitious materials and aggregates of different proportions and their characteristic compressive strength was tabulated. The appropriate mix design having adequate compressive strength and floating property was selected. Multiple mix designs were selected for the inner layer and outer layer respectively. The paper gives a detailed description regarding the hull design, mix design, construction and other relevant details to construct a concrete canoe.

\subsection{Materials Used}

i. Cementitious materials

- Old Portland cement

- Fly ash

- Metakaolin

- Silica fume

ii. Fibres

iii. Aggregates

- $\quad$ Lightweight expanded clay aggregates (LECA)

- $\quad$ Sand

- Perlite

- Vermiculate

- Glass Grit

- EPS Beads

iv. Admixture

- Polycarboxylate Ether

v. Reinforcements

- Primary: Glass Fibre Mesh

- Secondary: Glass Fibre Strand Mat (mentioned in fig 1)

- Tertiary: Galvanized Iron mesh 


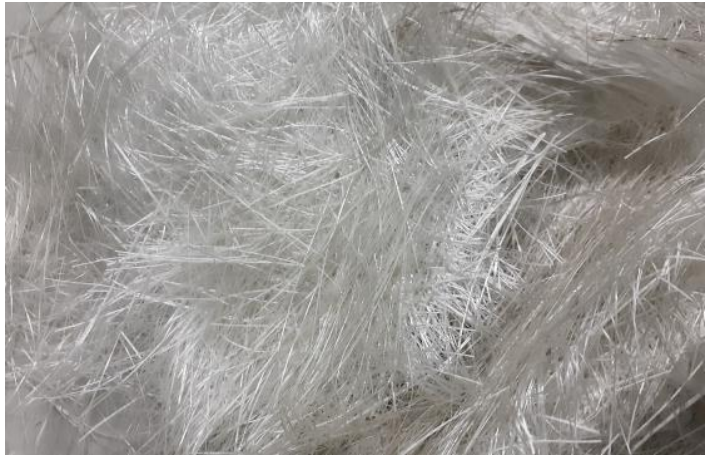

Fig -1: The Glass Fibre Strand Mat

\subsection{Methodology}

Canoes are usually built to showcase their stability and light weight nature. In this study, the preliminary and most fundamental aim was to create a stable structure which is lightweight in nature. Suitable materials were selected for the concrete mixture initially. The mix was based on trial and error method where each material of the concrete mix was separately evaluated and their percentage by ratios differed to create the perfect and balanced mix. Out of the several mixes obtained, the floating characteristics and strength parameters were analyzed thoroughly. The mix chosen for the construction of canoe was selected after numerous trials and was further tested to determine its behavior[7]. Once the mix was chosen, then next task was to design the structure of the canoe. The structure of the canoe was designed in ANSYS and it was then examined and evaluated based on the loads acting on the canoe such as uplift pressure, the load of the paddlers and the self-weight of structure. Based on this the design was reckoned and the mold was hence to be made.

For casting the canoe, a male mold was made using High density thermocol. The requires shape of the mold from high density thermocol was obtained after a long and cumbersome process of sanding and cutting. Two different mixes were used for casting out the canoe. The mixes differed only in the materials used between them. This first mix did not use LECA while the second mix used LECA. The first mix was applied to the base layer, the second mix was used in the intermediate layer and finally the last layer was again made up of the first mix. Reinforcements were used in between these layers to ensure load resistance. Finally, it was then given a wash by using the Alccofine 1203 mixed with cement.

\section{MIX DESIGN}

Through trial \& error method the water cement ratio was fixed as 0.4 for M25 grade of concrete. Cement and aggregates were partially replaced with supplementary cementitious \& lightweight materials[1]. The replacements were done with an aim to reduce the concrete density without affecting much of its strength aspect as well. The mix has been shown in fig 2 .

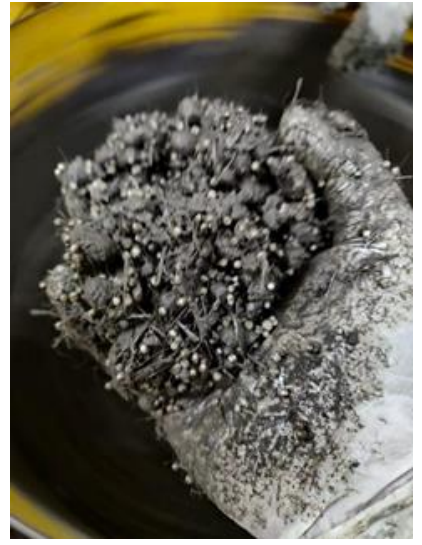

Fig -2: The designed mix

\section{- Cementitious}

OPC 53 Grade cement was used for the mix and was partially replaced with fly ash (5\%), metakaolin (10\%) and silica fume $(10 \%)$. The reaction rate of metakaolin is very rapid and helps to enhance compressive strength even at early stages with the enhanced production of CSH Gel. ASTM C618 and AASHTO M 295 classify metakaolin as a Class N (or natural) pozzolan. Due to its high surface area and high reactivity, relatively small additions are typically required.

The use of silica fume and fly ash in conjunction with metakaolin had a vital impact on the early strength development and increased the pozzolanic nature of the concrete mix.

The remaining $75 \%$ were OPC and was provided up to this level to ensure a good binding between cementitious materials (SCMs) \& aggregates and to produce enough calcium hydroxide upon hydration to react with the silica content in SCMs there by producing more CSH Gel. Or else the excess silica content would not participate in Gel formation and it will only act as a filler material which in turn affect the strength of the concrete.

Since the specific gravity of the SCMs used is lower than the cement, it also contributed in the total reduction of concrete density.

The cementitious replacement levels and the specific gravity of the materials has been listed in the table 1 given below:

Table-1: Specific Gravity of Cementitious materials

\begin{tabular}{|c|c|c|c|}
\hline Sl. No. & Materials & $\begin{array}{l}\text { Replacement } \\
\text { In \% }\end{array}$ & Specific Gravity \\
\hline 1. & OPC & $75 \%$ & 3.12 \\
\hline 2. & Fly Ash & $5 \%$ & 2.2 \\
\hline 3. & Metakaolin & $10 \%$ & 2.3 \\
\hline 4. & Silica Fume & $10 \%$ & 2.2 \\
\hline
\end{tabular}

- Fine Aggregate

In order to reduce the density of the concrete, much importance was given to material selection especially fine aggregate replacements and its quantity. M-Sand having specific gravity of 2.6 has been partially replaced with materials of lower specific gravity such as Expanded Polystyrene (EPS) beads, perlite, glass grit and vermiculite with a specific gravity of $0.046,0.32,2.5 \& 0.05$. The percent replacement has been shown in table 2 . 
When perlite is combined with cement as an aggregate replacement, it is much lighter than conventional concrete, thereby providing real structural design and floating capability. EPS bead is also a lightweight rigid foam material that is made by the polymerization of styrene. Fine aggregates were replaced with $35 \%$ of perlite and EPS beads simultaneously. Thus, concrete with perlite \& EPS beads showed a remarkable reduction in the density of concrete, making it lightweight and also $5 \%$ of vermiculite was used to partially replace M-Sand for enhancing lightweight properties. Vermiculite is abundantly available as a waste material and is effectively reused in this study by considering the sustainability aspect[6]. Since perlite, EPS beads and vermiculite are lightweight and have less strength, it readily affected the characteristic strength of the concrete. In order to counteract reduction in strength, $10 \%$ of glass grit was used in the partial replacement of fine aggregates. Being amorphous and containing relatively large quantities of silicon and calcium, glass is, in theory, pozzolanic or even cementitious in nature when the particle size is less than 75 microns.

Table-2: Specific Gravity of Fine Aggregates

\begin{tabular}{|c|c|c|c|}
\hline SI No. & Materials & $\begin{array}{l}\text { Replacement in } \\
\%\end{array}$ & Specific Gravity \\
\hline 1. & M-Sand & $15 \%$ & 2.6 \\
\hline 2. & Perlite & $35 \%$ & 0.32 \\
\hline 3. & EPS Beads & $35 \%$ & 0.046 \\
\hline 4. & Vermiculite & $5 \%$ & 0.05 \\
\hline 5. & Glass Grit & $10 \%$ & 2.5 \\
\hline
\end{tabular}

\section{- Coarse Aggregate}

The mix that has been used in the intermediate layer is done with cementitious materials + fine aggregates + coarse aggregates. Here, instead of gravel as coarse aggregate, Lightweight Expanded Clay Aggregate (LECA) was used as a replacement by volume i.e., coarse aggregate is replaced with $100 \%$ of LECA (below $5 \mathrm{~mm}$ ) by its volume. LECA is a special type of lightweight aggregate that has been pelletized and fired in a rotary kiln at a very high temperature. As it is fired, the organic compounds burn off forcing the pellets to expand and become honeycombed while the outside surface of each granule melts and is sintered. The resulting ceramic pellets are lightweight, porous and have a high crushing resistance and also played a vital role in the reduction of concrete density. The only drawback while using LECA is that it has high water absorption thereby increasing the water demand. Therefore, it has been used in saturated surface dry condition. The replacement level and the specific gravity of material has been listed in table-3 below:

Table-3: Specific Gravity of Coarse Aggregate

\begin{tabular}{|c|c|c|c|}
\hline SI No. & Materials & Replacement in \% & Specific Gravity \\
\hline 1. & LECA & 100 & 0.56 \\
\hline
\end{tabular}

\section{- Superplasticizer}

Polycarboxylate Ether (PCE) based superplasticizer were used to reduce water cement ratio without affecting the workability of the mixture which in turn enhances the mechanical properties upon replacement. The superplasticizer has been shown in fig 3.

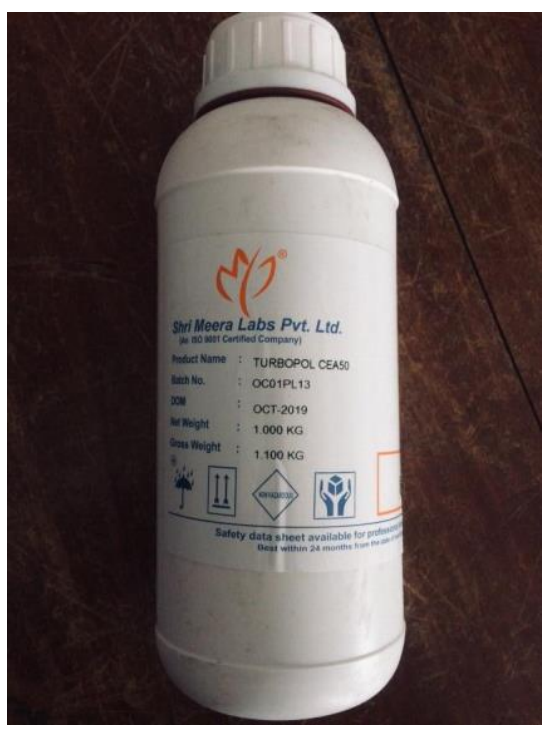

Fig -3: Polycarboxylate Ether (PCE)

With PCE superplasticizers, more fly ash or other supplementary cementitious materials can be used and also improves adhesion between aggregate \& mortar interface as well as new \& old concrete interfaces. The dosage of PCE super plasticizer were opted as $0.9 \%$ of total cementitious materials.

\section{- Fibre}

Fibre is usually added in concrete to control cracking due to plastic shrinkage and drying shrinkage. Here, the fibre used is Strongcrete Polypropylene Fibre and is added in volume fraction. The dosage of fibre is limited to $0.3 \%$ of total volume and it is observed that higher dosages resulted in the formation of lumps, less workability and reduced compressive strength. With trial and error method, $0.3 \%$ is opted as the optimum dosage value and thus resulted in increased resistance to plastic shrinkage during curing, improved structural strength, reduced steel reinforcement requirements and reduced crack width.

\subsection{Tests Conducted}

Slump test: It was performed to check the workability of freshly made concrete. A slump value of $\mathbf{5 2} \mathbf{m m}$ was obtained from the test performed. The workability of concrete was given utmost importance since it was necessary to ensure that the thickness of the canoe is maintained throughout while placing the concrete on the mold.

Compressive Strength: The compressive strength test was conducted using a Universal Testing Machine. Concrete sample cubes of size $0.15 \mathrm{~m} \times 0.15 \mathrm{~m} \times 0.15 \mathrm{~m}$ was used for the test.

Tensile Strength: Cylinders were casted for performing the split tensile strength test.

Flexural Strength: A heavy beam specimen was casted for the purpose of this test. 


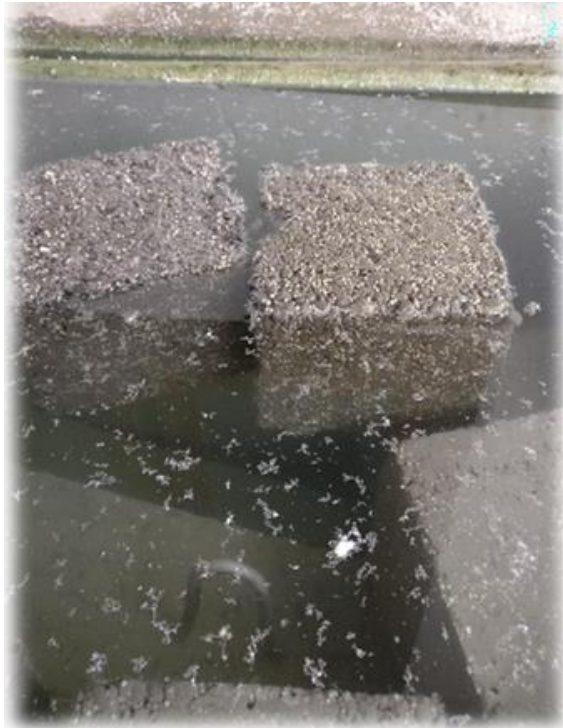

Fig -4: The curing process of the floating cubes

Table-4: Strengths of the mix 1 (with LECA)

\begin{tabular}{|c|c|c|c|c|}
\hline $\begin{array}{c}\text { Sample } \\
\text { no. }\end{array}$ & $\begin{array}{c}\text { No. of } \\
\text { days }\end{array}$ & $\begin{array}{c}\text { Compressive } \\
\text { strength (In } \\
\text { MPa) }\end{array}$ & $\begin{array}{c}\text { Tensile } \\
\text { Strength } \\
\text { (In MPa) }\end{array}$ & $\begin{array}{c}\text { Flexural } \\
\text { Strength (In } \\
\text { MPa) }\end{array}$ \\
\hline 1. & 7 & 5.13 & 0.49 & 0.76 \\
\hline 2. & 14 & 6.51 & 0.6 & 0.92 \\
\hline 3. & 28 & 7.2 & 0.734 & 1.12 \\
\hline
\end{tabular}

Table-5: Strengths of the mix 2 (without LECA)

\begin{tabular}{|c|c|c|c|c|}
\hline $\begin{array}{c}\text { Sample } \\
\text { no. }\end{array}$ & $\begin{array}{c}\text { No. } \\
\text { of } \\
\text { days }\end{array}$ & $\begin{array}{c}\text { Compressive } \\
\text { strength }(\text { In } \\
\text { MPa) }\end{array}$ & $\begin{array}{c}\text { Tensile } \\
\text { Strength } \\
\text { (In MPa) }\end{array}$ & $\begin{array}{c}\text { Flexural } \\
\text { Strength } \\
\text { (In MPa) }\end{array}$ \\
\hline 1. & 7 & 6.21 & 0.64 & 0.98 \\
\hline 2. & 14 & 7.96 & 0.81 & 1.23 \\
\hline 3. & 28 & 8.8 & 0.90 & 1.42 \\
\hline
\end{tabular}

The curing process of the floating cubes has been shown in fig 4 .

\section{HULL DESIGN AND STRUCTURAL ANALYSIS}

In hull design and structural analysis, focus was on speed, maneuverability and stability of a hull i.e. geometry and crosssectional shape. A semi round bottom shape with a pointed center was chosen to ensure more strength to the canoe as well as the maneuverability for traversing the path of the movement for the canoe. An account of the paddler's size was taken to fix the dimension of the canoe.

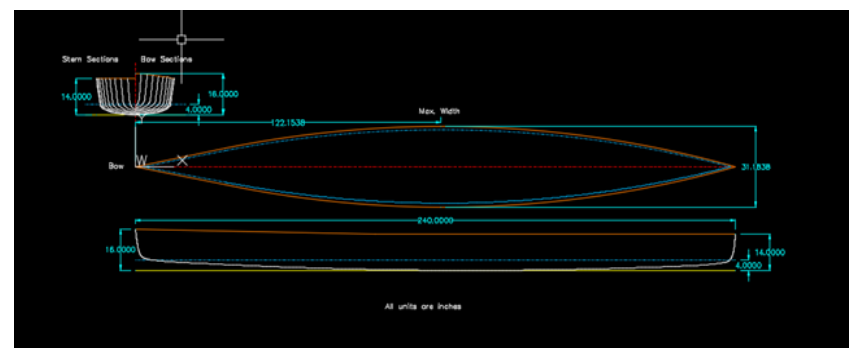

Fig -5: The CAD drawings of the canoe
The bow and the stern were provided with sharp edges to increase the turning ability and to maintain a smooth course. Increasing maneuverability requires more rocker in both stern and bow section and allow water to flow laterally during bowinitiated turns. With a square stem the canoe would have a good tracking whereas, a round stem is good in terms of maneuverability. A reinforcement system that would provide sufficient capacity for all loading cases was finalised. The completeness of canoe is based on speed and stability. Hence the round bottom with pointed center was chosen for the canoe. The CAD model has been shown in fig 5 .
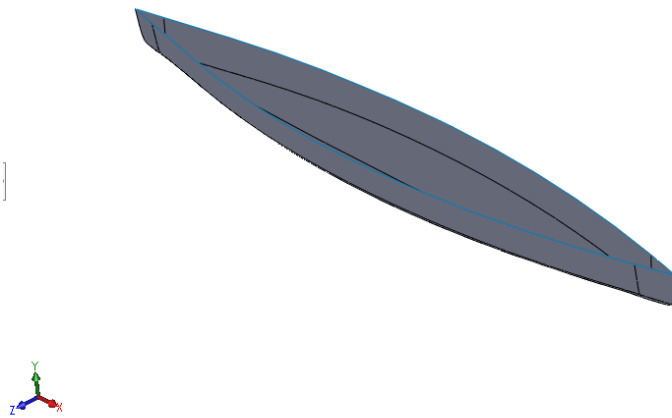

Fig -6: The Solidworks model of the canoe

The design in SOLIDWORKS (as shown in fig 6) gave out an excellent image for the canoe aesthetically as well as structurally. The design was firstly initiated in AutoCAD software, after the needed alterations, the image was detailed and a 3D drawing was done in SOLIDWORKS. The primary objective was to ensure that the canoe would withstand all reasonable loading and handling stresses. Structural analysis was carried out by modeling the canoe as a two dimensional simply-supported beam in static equilibrium. The design was created considering the weights of the paddlers as point loads, each weighting approximately $800 \mathrm{~N}$. Load application shown in fig 7.

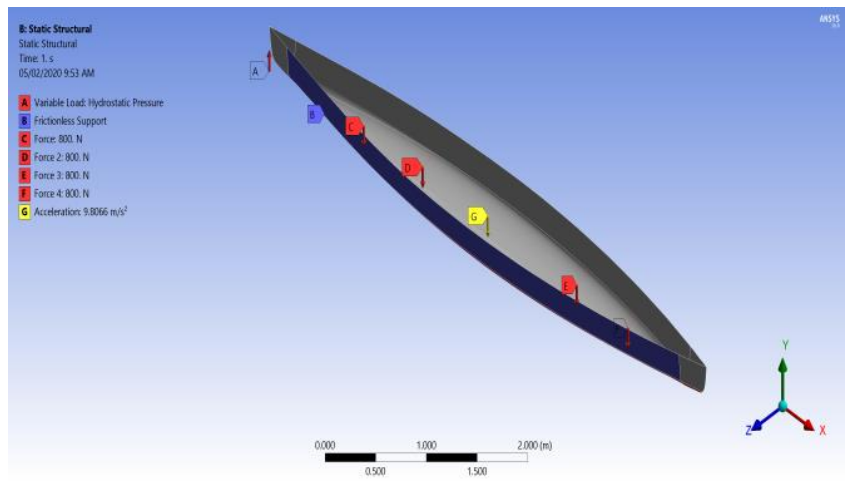

Fig -7: The application of loads and boundary conditions in ANSYS

A hydrostatic buoyancy force would be acting along the bottom in a trapezoidal shape, increasing buoyant force counteracting the canoes weight towards the widest point, and the paddler's point loads. Maximum compressive and tensile forces over the entire length became the critical stresses for which the concrete mix and reinforcement would withstand. Based on the results of the analysis as well as the effect of the negative and positive forces acting on the canoe, the total shear force and bending 
moment was systematically computed. This provided sufficient data in designing a suitable and efficient structural and reinforcement design for the concrete canoe. A three layered reinforcement design for withstanding the incoming loading was provided. The first layer was a grout mix added with Alccofine and cement to the male mold. The first mix was then followed by a layer of lightweight concrete without the use of any coarse aggregate The deformation forces are shown in fig 8 .

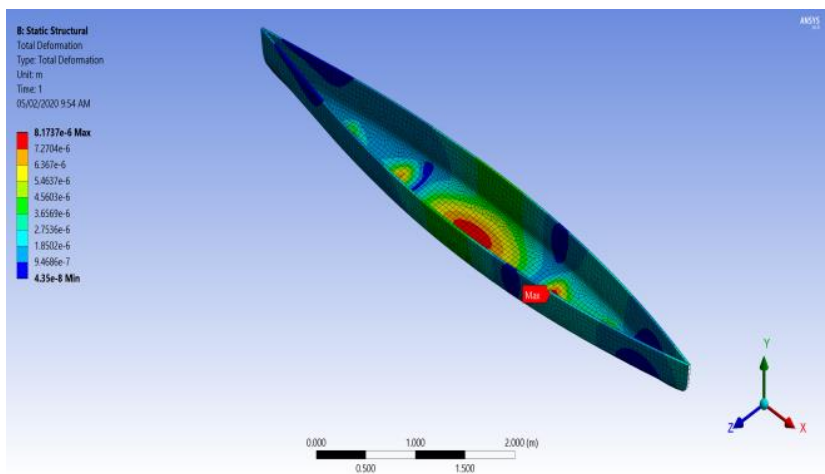

Fig -8: The total deformation forces occurring on the canoe analyzed via ANSYS

The primary reinforcement comprised of Fibre glass mesh. Once this layer was set out, the second layer with coarse aggregate was then pasted on top of this mix binding them together. The secondary reinforcement was then set up using galvanized iron mesh. A safe buffer layer of tertiary reinforcement was then provided for the canoe. This layer comprised of Glass fibre strand mat. This layer made an interlocking effect between the respective individual layers.

\section{DEVELOPMENT AND TESTING}

The target was to reduce the weight of the canoe with a proper mix design to ensure floatation. Ordinary Portland cement(OPC) was used as the primary cementitious material.. For the first layer, a mix without coarse aggregate (LECA) was provided. Soon after placing it, it was covered with Glass Fibre Mesh as the first reinforcement layer.

The second layer mix was done with both the fine aggregates and LECA as coarse aggregates. It is then covered using Glass Fibre Strand Mat as the second reinforcement layer and another layer of cementitious paste using cement and Alccofine was provided. Galvanized iron mesh was provided as the final reinforcement layer which is then protected by a third (final) layer of mix without coarse aggregates (LECA). The mix also comprised of various fine aggregate replacement materials like Perlite, Vermiculite, Glass Grits, EPS Beads, MSand. The Polypropylene fibres used in the mix ensures interlocking of materials and the increase in tensile strength. A highperformance water reducing Polycarboxylate ether super plasticizer was used as an admixture. The water to cementitious materials ratio was fixed to 0.40 .

\section{CONSTRUCTION OF THE CANOE}

Firstly, the mold selection process began with researching on making a manufactured mold. This strategy would create a smoother and more precise mold, while also cutting down on mold manufacturing person-hours, but was deemed too expensive for the budget.

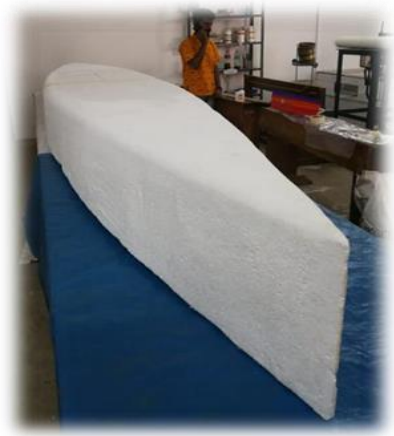

Fig -9: The Male Mold

A male mold (as shown in fig 9) was selected to better suit the requirements since less materials were only needed for this compared to a female mold. The male mold created an outer hull that was smoother, and thus required less sanding while maintaining the designed hull shape. To create the mold, a 3-D model of the canoe was created in solid works. Structural analysis was conducted in order to determine the properties of the canoe such as load applied on it and deformation taking place after the load is applied. After the process of structural analysis, we moved on to the process of cutting out the mold. High density thermocol canoe mold was made of $6 \mathrm{~m} \times 0.9 \mathrm{~m} \times 0.6 \mathrm{~m}$ dimensions.

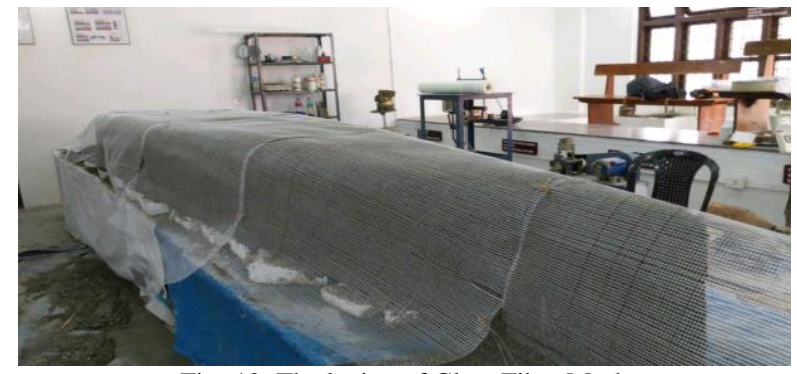

Fig -10: The laying of Glass Fiber Mesh

The process of making the concrete canoe started by applying the cement grout on top of the mold. The first layer of mix was applied which consisted of fine aggregates and cement.

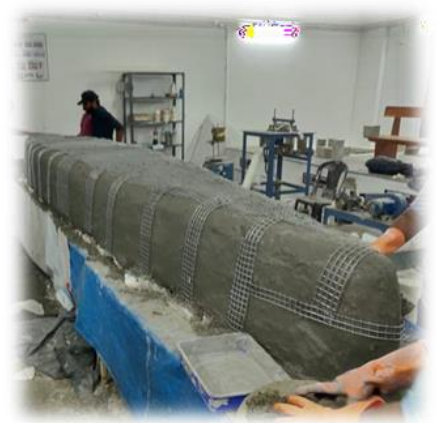

Fig -11: Providing the Galvanized Iron Mesh

On top of the first layer, grout and fibre glass mesh was wrapped which is said to be the primary reinforcement. Then the second layer of mix consisting of fine aggregates, coarse aggregates and cement was applied on top of it. After the second layer galvanized iron mesh was wrapped on top of it representing the secondary reinforcement. Under iron mesh, 
glass fibre chopped strand mat was wrapped on top of the second layer of the mix.

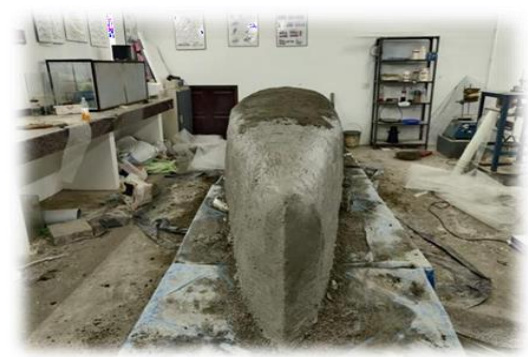

Fig -12: The finishing of the Final Layer

In the end, the third layer of mix consisting of fine aggregate and cement was applied. For final finishing cement grout was applied too. Then the concrete canoe was kept for curing for a period of 28 days. Constructing processes shown in fig $10,11,12$. The end product is shown in fig 13 and the floating canoe is shown in fig 14 .

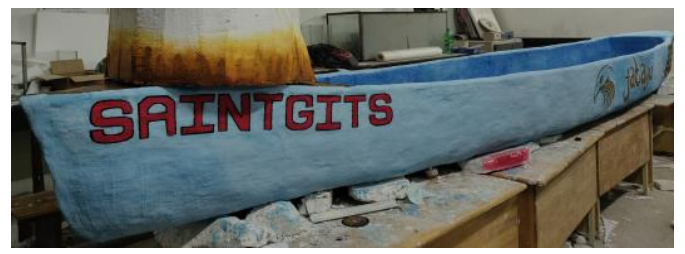

Fig -13: The Finished product

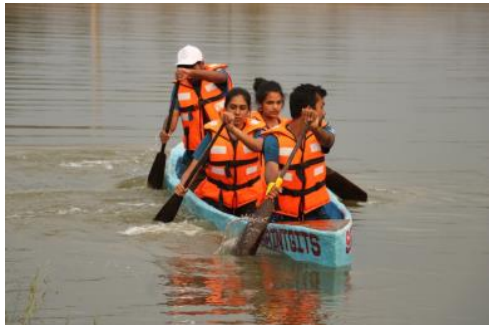

Fig -14: The Floating concrete Canoe

\section{CONCLUSIONS}

The actual replacement of fibre/wood canoes with concrete canoes in the commercial world still stands far from reality. The high material cost and challenges in figuring out the most suitable mix design makes it a hideous process. The suitable mix design proportions for the required compressive strength of concrete can only be attained through numerous trial and error procedures. Further study and research need to be carried out in the field of light weight concrete to ensure low density without compromising the compressive strength.

In order to conclude, from this study one can state that the commercial usage of concrete canoes seems possible with further experimentation and study using materials with lower relative density.

\section{ACKNOWLEDGEMENT}

First of all, we would like to thank Er. Cherian C.K for his valuable support and sheer enthusiasm which helped us spearhead this project to the next level. It was because of him that all of this was possible. Then we would like to thank Er.
Jithin Kurian Andrews for the predetermination and motivation that he has fuelled in us. It was his words of wisdom that helped us clear the paths of the many hurdles that we encountered. Now I would like to thank Dr. Nivin Philip for the extensive support that he has offered to us earnestly. It would not have been possible without his immense support and extraordinary technical usance. We would then like to thank Dr. Reebu Z. Koshy for his undying fidelity that he had offered us during the course of our journey. We would also like to thank all our faculties and colleagues for their support and love. Last but not the least; we would like to thank our brothers and sisters of the ASCE SAINTGITS chapter who has profoundly made all of this possible. It would have been blank without their sustenance and patronage. Several sleepless nights, work shifts of five to six hours and abstained from all other entertainment for around two months resulted in this piece of work. We am truly indebted to our team for all of these. This is our tribute to their relentless efforts.

\section{REFERENCES}

[1] IS 456:2000 Plain and reinforced concrete code book

[2] M. S. Shetty, S. Chand Publications, Concrete Technology, 24 ${ }^{\text {th }}$ Edition

[3] H. K. Sarje, A.S. Autade, "Study of performance of light weight concrete", International Journal of Latest Trends in Engineering and Technology, ISSN: 2278-621X, Vol. 4, Issue 4, Nov 2014, PP 139-141

[4] B. Nagashree, DR. S. Vijaya, "Development light weight concrete by blending with LECA and cinder", International Journal for Scientific Research \& Development, ISSN (online): 2321-0613, Vol. 3, Issue 04, 2015

[5] K.M Lakshmi, M.K. MV Ratnam, DR. U. Rangaraju, "Experimental study on light weight aggregate concrete with pumice stone, silica fume and fly ash as a partial replacement of coarse aggregate" International Journal of Innovative Research in Science, Engineering and Technology, ISSN 2319-8753, Vol. 3, Issue 12, Dec 2014, PP 18130-18138

[6] ACI 213R-14 (2014). Guide for structural lightweight-aggregate concrete, ACI 213R-14, American Concrete Institute, Farmington Hills, MI, USA

[7] P. Shafigh, M. Mahmoud Hassanpour, S. V. Razavi, M. Kobraei, “An investigation of flexural behaviour of reinforced light concrete beams", International Journal of the Physical Sciences, ISSN 1992 1950, Vol.6(10), May-2011, PP 2414-2421

\section{BIOGRAPHIES}

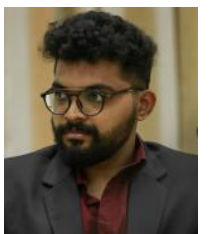

Sanjay Jayakumar

Project Manager (Concrete Canoe)

Department of Civil Engineering

SAINTGITS COLLEGE OF ENGINEERING

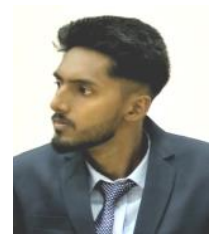

Abhishek Kurian

Structural Head (Concrete Canoe)

Department of Civil Engineering

SAINTGITS COLLEGE OF ENGINEERING 
Febin T Zachariah

Mix Design Head (Concrete Canoe)

Department of Civil Engineering

SAINTGITS COLLEGE OF ENGINEERING

Dr. Nivin Philip

Faculty In charge (Concrete Canoe)

Associate Professor

Department of Civil Engineering

SAINTGITS COLLEGE OF ENGINEERING 